\title{
Evaluation of Nickel-Aluminium Complex Hydroxide for Adsorption of Chromium(VI) Ion
}

\author{
Fumihiko Ogata, ${ }^{a}$ Takehiro Nakamura, ${ }^{a}$ Megumu Toda, ${ }^{b}$ Masashi Otani, ${ }^{b}$ and \\ Naohito Kawasaki*,a,c \\ ${ }^{a}$ Faculty of Pharmacy, Kindai University; 3-4-1 Kowakae, Higashi-Osaka, Osaka 577-8502, Japan: \\ ${ }^{b}$ Kansai Catalyst Co., Ltd.; 1-3-13 Kashiwagi-cho, Sakai-ku, Sakai 590-0837, Japan: and \\ ${ }^{c}$ Antiaging Center, Kindai University; 3-4-1 Kowakae, Higashi-Osaka, Osaka 577-8502, Japan. \\ Received September 11, 2019; accepted October 29, 2019
}

In this study, nickel-aluminium complex hydroxides at different molar ratios (nickel-aluminium $=1: 2$, $1: 1,2: 1,3: 1$, and 4:1, referred to as NA12, NA11, NA21, NA31, and NA41) were prepared, and their adsorption capability for chromium(VI) ion was investigated. Firstly, physicochemical characteristics (SEM images, X-ray diffraction (XRD) patterns, specific surface area, amount of hydroxyl groups, and surface pH) of nickel-aluminum complex hydroxide were evaluated. The amount of chromium(VI) ion adsorbed onto NA11 $(15.3 \mathrm{mg} / \mathrm{g})$ was greater than that adsorbed onto the other adsorbents. This research elucidated that the amount of chromium(VI) ion adsorbed using nickel-aluminium complex hydroxide was related to the adsorbent surface properties $(r=0.818-0.875)$. Subsequently, the adsorbent (NA11) surface before and after adsorption of chromium(VI) ion was evaluated, and chromium energy (577 and $586 \mathrm{eV})$ detected after adsorption onto the NA11 surface. These results revealed that the NA11 surface properties were very important for the removal of chromium(VI) ion from aqueous solution. In addition, the effects of $\mathrm{pH}$, contact time, and temperature on the adsorption of chromium(VI) ion were evaluated. We confirmed a high recovery percentage of chromium(VI) ion when using sodium hydroxide solution at $10-1000 \mathrm{mmol} / \mathrm{L}$ (approximately greater than $80 \%$ ) in this experimental condition. Thus, NA11 is a promising adsorbent for the removal of chromium(VI) ion from aqueous solution.

Key words nickel-aluminium complex hydroxide; chromium(VI) ion; adsorption

\section{Introduction}

Chromium contamination of water is a severe problem worldwide and has had a great impact on both aquatic environmental safety and human health. ${ }^{1,2)}$ Chromium(VI) is generally present in wastewaters that originate from various industrial processes, such as tanning, electroplating, metal processing, manufacturing, steel fabrication, petroleum refining processing, and agricultural runoff. ${ }^{3)}$ Chromium(VI) exists in the form of extremely soluble and highly toxic chromate ions $\left(\mathrm{HCrO}_{4}^{-}, \mathrm{CrO}_{4}^{2-}\right.$, and $\mathrm{Cr}_{2} \mathrm{O}_{7}^{2-}$ ) that can transfer freely. ${ }^{4)} \mathrm{In}$ addition, a high level of chromium(VI) contaminants in drinking water can be carcinogenic, possibly leading to hepatic or renal damage, gastrointestinal irritation, central nervous system irritation, etc. ${ }^{5-7)}$ Therefore, chromium(VI) compounds are classified under category Group 1 "carcinogenic to $h u$ mans" by the International Agency for Research on Cancer, and the WHO and U.S. Environmental Protection Agency recommend that the maximum level of chromium(VI) in drinking water be $0.05 \mathrm{mg} / \mathrm{L}$ and that the discharge limit from industries be $0.10 \mathrm{mg} / \mathrm{L}^{2)}$

On the other hand, chromium is a relatively rare metal with several applications in the field of technology. It is stockpiled in Japan because its supply depends significantly on imports and thus is subject to shortages in global supply. The Republic of South Africa is the largest producer of chromium in the world. Japan is one of the main consumers of rare metals (e.g., chromium) in the world, but there are insufficient reserves of rare metals. ${ }^{8,9)}$ Therefore, it is very important to develop techniques for both the removal and for the recycling of chromium in environmental water.

Various methods for directly trapping chromium(VI) ion from water have been developed. These include adsorption, membrane filtration, chemical precipitation, reverse osmosis, electrodialysis, and some others. ${ }^{1)}$ Among them, adsorption is considered favorable and feasible due to its high efficiency, short operation time, flexibility or simplicity of design, and ease of operation. ${ }^{3)}$

Recently, the physicochemical characteristics and feasibility of metal complex hydroxides have received an increasing amount of attention, and application of these compounds has been evaluated. Previous studies have reported the removal of chromium(VI) ion from aqueous solution using $\mathrm{Ca}-\mathrm{Al}$ hydrotalcite (prepared through co-precipitation method using calcium and aluminium ions), nano-hydrotalcite/ $\mathrm{SiO}_{2}$ composite, hydrotalcite/carbon composite, $\mathrm{Mg}$-Al hydrotalcite (prepared through co-precipitation method using magnesium and aluminum ions) supported kaolin clay, carboxymethylcellulose-layered double hydroxide (CMC-LDH) beads, solgel hydrotalcite-like compounds, bamboo biochar, straw biochar, pig manure biochar, and biochar with magnesium and aluminum-layered double hydroxide intercalated with ethylenediaminetetraacetic acid etc. ${ }^{1,3,5,10-14)}$ In addition, our previous work focused on enhancing the removal of toxic anionic compounds (heavy metals, inorganic nitrogen, phosphate ion, etc.) from water. $^{15-19)}$ We found that nickel-aluminium complex hydroxide showed excellent adsorption of toxic anionic compounds from aqueous solution. ${ }^{20)}$ However, there are no reports pertaining to the fundamental study or application 
of adsorption of chromium(VI) ion (toxic anionic compound) from aqueous solution. Thus, if chromium(VI) ion adsorption onto nickel-aluminium complex hydroxide is developed, its value and applicability would increase substantially and useful information for elucidating an adsorption/recycle mechanism for chromium(VI) ion would be obtained.

In this work, nickel-aluminium complex hydroxide was prepared for the removal/recycle of chromium(VI) ions from aqueous solution. The adsorbent characteristics were investigated, the kinetic and isothermal behaviours were evaluated, and the parameters influencing chromium(VI) ion adsorption, including solution $\mathrm{pH}$, temperature, and contact time, were studied. Finally, the desorption of chromium(VI) ions from nickel-aluminium complex hydroxide were evaluated to assess the applicability of the method in water environmental fields.

\section{Experimental}

Materials Nickel-aluminum complex hydroxides with molar ratios of $\mathrm{Ni}^{2+}$ to $\mathrm{Al}^{3+}$ of $0.5,1.0,2.0,3.0$, and 4.0, referred to as NA12, NA11, NA21, NA31, and NA41, respectively, were prepared by the co-precipitation method. Morphologies of the adsorbents were determined by scanning electron microscopy (SEM, SU1510, Hitachi High-Technologies Co., Japan). Crystallinities and the number of hydroxyl groups were measured by X-ray diffractometry (XRD, MiniFlex II, Rigaku, Japan) and the fluoride ion adsorption method. ${ }^{21)}$ The specific surface area was measured using a NOVA4200e specific surface analyzer (Yuasa Ionic, Japan). Surface $\mathrm{pH}$ of the adsorbents was measured by a digital $\mathrm{pH}$ meter F-73 (HORIBA, Ltd., Japan). Briefly, the adsorbent (0.1 g) was added to distilled water of $\mathrm{pH} 7.0(50 \mathrm{~mL})$, the suspension was shaken for $2 \mathrm{~min}$ at $25^{\circ} \mathrm{C},{ }^{22)}$ and then filtered through a $0.45 \mu \mathrm{m}$ membrane filter.

Elemental analysis and electron spectroscopy were carried out using an electron microanalyzer (EPMA, JXA-8530F, JEOL, Japan) and an X-ray photoelectron spectroscopy system (AXIS-NOVA, Shimadzu Co., Ltd., Japan), respectively. The sample solution of chromium(VI) ion was prepared from chromium standard solution $\left(\mathrm{K}_{2} \mathrm{Cr}_{2} \mathrm{O}_{7}\right.$ in $\left.0.1 \mathrm{~mol} / \mathrm{L} \mathrm{HNO}_{3}\right)$. The solution $\mathrm{pH}$ was adjusted by hydrochloric acid and sodium hydroxide solution. Potassium chloride, potassium sulfate, and potassium nitrate were purchased from Wako Pure Chemical Corporation, Japan. All reagents in this experiment were special reagent grade.

Amount of Chromium(VI) Ion Adsorbed The adsorbent $(0.05 \mathrm{~g})$ was added to $50 \mathrm{~mL}$ of a $100 \mathrm{mg} / \mathrm{L}$ chromium(VI) ion solution. The suspension was shaken at $100 \mathrm{rpm}$ for $24 \mathrm{~h}$ at $25^{\circ} \mathrm{C}$. Subsequently, the sample was filtered through a $0.45 \mu \mathrm{m}$ membrane filter, and then the filtrate was analyzed using inductively coupled plasma optical emission spectroscopy (ICPOES, iCAP-7600, Thermo Fisher Scientific Inc., Japan). The amount of adsorbed was calculated using Eq. (1):

$$
q=\left(C_{0}-C_{e}\right) V / W
$$

where $q$ is the amount of chromium(VI) ion adsorbed $(\mathrm{mg} / \mathrm{g})$, $C_{0}$ is the initial concentration $(\mathrm{mg} / \mathrm{L}), C_{e}$ is the equilibrium concentration $(\mathrm{mg} / \mathrm{L}), V$ is the solvent volume $(L)$, and $W$ is the weight of the adsorbent $(\mathrm{g})$.

Effect of pH, Contact Time, and Temperature on the Adsorption of Chromium(VI) Ion Firstly, to evaluate the effect of $\mathrm{pH}$, several samples were prepared by adding $0.1 \mathrm{~g}$ of NA11 to $50 \mathrm{~mL}$ of $100 \mathrm{mg} / \mathrm{L}$ chromium(VI) ion solution. The suspension $\mathrm{pH}$ was adjusted by hydrochloric acid or sodium hydroxide solution to obtain a $\mathrm{pH}$ range of solutions of 2.0-12.0, and then the sample solutions were shaken at $100 \mathrm{rpm}$ for $24 \mathrm{~h}$ at $25^{\circ} \mathrm{C}$. Secondly, to evaluate contact time, NA11 $(0.1 \mathrm{~g})$ was added to $50 \mathrm{~mL}$ of $100 \mathrm{mg} / \mathrm{L}$ chromium(VI) ion solution, and suspensions were shaken for $1,3,5,8,12$, 16,20 , and $24 \mathrm{~h}$ at $100 \mathrm{rpm}$ at $25^{\circ} \mathrm{C}$. Finally, to evaluate the effect of temperature, NA11 $(0.1 \mathrm{~g})$ was added to $50 \mathrm{~mL}$ of chromium(VI) ion solution with concentrations ranging from 10 to $100 \mathrm{mg} / \mathrm{L}$. The suspensions were shaken for $24 \mathrm{~h}$ at $100 \mathrm{rpm}$ at 5,25 , and $45^{\circ} \mathrm{C}$. The amount of chromium(VI) ion adsorbed in each case was calculated using Eq. (1).

Adsorption and Desorption Capability of NA11 for Chromium(VI) Ion after Treatment with Sodium Hydroxide Solution The adsorbent (NA11, $0.1 \mathrm{~g}$ ) was added to $50 \mathrm{~mL}(100 \mathrm{mg} / \mathrm{L})$ of the chromium(VI) ion solution. The suspension was shaken at $100 \mathrm{rpm}$ for $24 \mathrm{~h}$ at $25^{\circ} \mathrm{C}$. Subsequently, the suspension was filtered through a $0.45 \mu \mathrm{m}$ membrane filter, and the filtrate was analyzed using ICP-OES. The amount of chromium(VI) ion adsorbed was calculated by using Eq. (1). After adsorption, the adsorbent was collected, dried, and then used for the desorption experiment. The collected NA11 was added to $100 \mathrm{~mL}$ of sodium hydroxide solution at $1,10,100$, and $1000 \mathrm{mmol} / \mathrm{L}$. Then, the suspensions were shaken for $24 \mathrm{~h}$ at $100 \mathrm{rpm}$ at $25^{\circ} \mathrm{C}$ and subsequently filtered through a $0.45 \mu \mathrm{m}$ membrane filter. The concentration of chromium(VI) ion released from the NA11 was measured by ICP-OES. The amount of chromium(VI) ion desorbed was calculated using Eq. (2):

$$
q=C_{e} V / W
$$

where $q$ is the amount desorbed $(\mathrm{mg} / \mathrm{g}), C_{e}$ is the equilibrium concentration $(\mathrm{mg} / \mathrm{L}), V$ is the solvent volume $(L)$, and $W$ is the weight of the adsorbent $(\mathrm{g})$.

In addition, the potential for repeated use of the NA11 in subsequent recoveries of chromium(VI) ion was evaluated by repeating the aforementioned treatment (adsorption and desorption treatment as one cycle) three times. Sodium hydroxide solution at a concentration of $1000 \mathrm{mmol} / \mathrm{L}$ was used in this experiment.

Effect of Coexistences on the Adsorption of Chromium(VI) Ion onto NA11 The adsorbent (NA11, $0.1 \mathrm{~g}$ ) was added to a $1 \mathrm{mmol} / \mathrm{L}$ chromium(VI) ion and chloride ion, sulfate ion, or nitrate ion binary solution $(50 \mathrm{~mL})$. The suspensions were shaken at $100 \mathrm{rpm}$ for $24 \mathrm{~h}$ at $25^{\circ} \mathrm{C}$. Subsequently, the suspensions were filtered through a $0.45 \mu \mathrm{m}$ membrane filter, and the filtrate was analyzed using ICP-OES and ion chromatography (DIONEX ICS-900, Thermo Fisher Scientific Inc., Japan). The amount of chromium(VI) ion adsorbed was calculated using Eq. (1).

Ion chromatography measurements were performed using the IonPac AS12A system $(4 \times 200 \mathrm{~mm}$, Thermo Fisher Scientific Inc., Japan). The mobile phase and the regenerate were $2.7 \mathrm{mmol} / \mathrm{L} \quad \mathrm{Na}_{2} \mathrm{CO}_{3}+0.3 \mathrm{mmol} / \mathrm{L} \quad \mathrm{NaHCO}_{3}$ and $12.5 \mathrm{mmol} / \mathrm{L}$ $\mathrm{H}_{2} \mathrm{SO}_{4}$, respectively. The flow rate was $1.5 \mathrm{~mL} / \mathrm{min}$ at ambient temperature. The micro-membrane filter suppressor was an AMMS 300 system $(4 \mathrm{~mm}$, Thermo Fisher Scientific Inc., Japan) and the sample volume was $10 \mu \mathrm{L}$. 
NA12

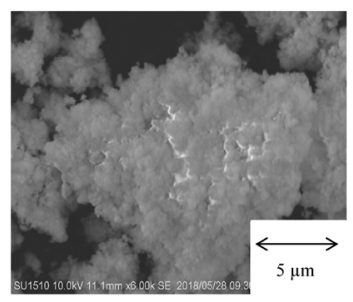

NA11

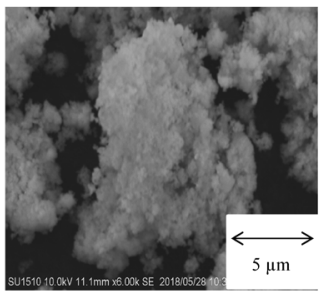

NA2 1

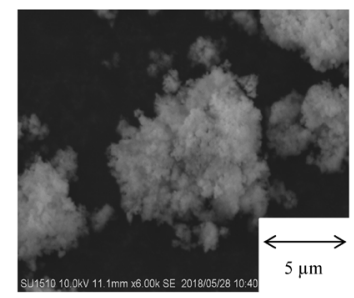

NA41
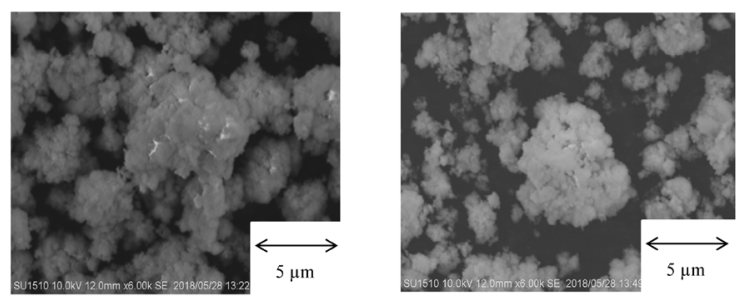

Fig. 1. SEM Images of Adsorbents

\section{Results and Discussion}

Characteristics of Adsorbents We previously reported the physicochemical properties of nickel-aluminium complex hydroxides of different molar ratios. We confirmed an irregular crystal system with increasing amounts of aluminium (Fig. 1). This change indicated that the constituent elements (nickel and aluminium) affect the crystal system. Figure 2 shows XRD patterns of the adsorbents. NA41 and NA31 had a highly crystalline nature, which decreased with increasing amounts of aluminium, suggesting that NA11 and NA12 are highly reactive (amorphous nature). The properties of the adsorbents are shown in Table 1. Specific surface area and amount of hydroxyl groups were higher for NA11 and NA12 than for other adsorbents. The constituent element ratios did not appear to affect the surface $\mathrm{pH}$ in this study. ${ }^{20)}$

Amount of Chromium(VI) Ion Adsorbed onto NA11 The amount of chromium(VI) ion adsorbed onto the various adsorbents is shown in Fig. S1. The amount adsorbed varied in the order of NA11 $(15.3 \mathrm{mg} / \mathrm{g}) \fallingdotseq \mathrm{NA} 12(14.9 \mathrm{mg} / \mathrm{g})>\mathrm{NA} 41$ $(12.1 \mathrm{mg} / \mathrm{g})>\mathrm{NA} 31 \quad(9.0 \mathrm{mg} / \mathrm{g})>\mathrm{NA} 21 \quad(2.7 \mathrm{mg} / \mathrm{g})$. These results indicate that the nickel and aluminium ratio of the adsorbent is very important for the removal of chromium(VI) ion from aqueous solution. In addition, we evaluated the relationships between the amount of chromium(VI) ion adsorbed and the properties of the adsorbents (Fig. S2). The correlation coefficients between amount adsorbed and surface $\mathrm{pH}$, amount of hydroxyl groups, and specific surface area were 0.833 , 0.818 , and 0.875 , respectively. These results indicate that the physicochemical properties of the adsorbent surface are very important for adsorption of chromium(VI) ion. Therefore, we observed the adsorbent surface before and after adsorption (Fig. 3). We confirmed that the amount of chromium was higher after adsorption, suggesting that one of the adsorption mechanisms of chromium(VI) ion by NA may involve a combination of electrostatic interaction, ligand exchange, and ion exchange. ${ }^{23)}$ Next, we measured the binding energy of the adsorbent surface (NA11) before and after the adsorption of chromium(VI) ion (Fig. 4). $\mathrm{Cr}(2 \mathrm{p})$ peaks at 577 and $586 \mathrm{eV}$ were detected and the $\mathrm{S}(2 \mathrm{p})$ peak intensity was reduced

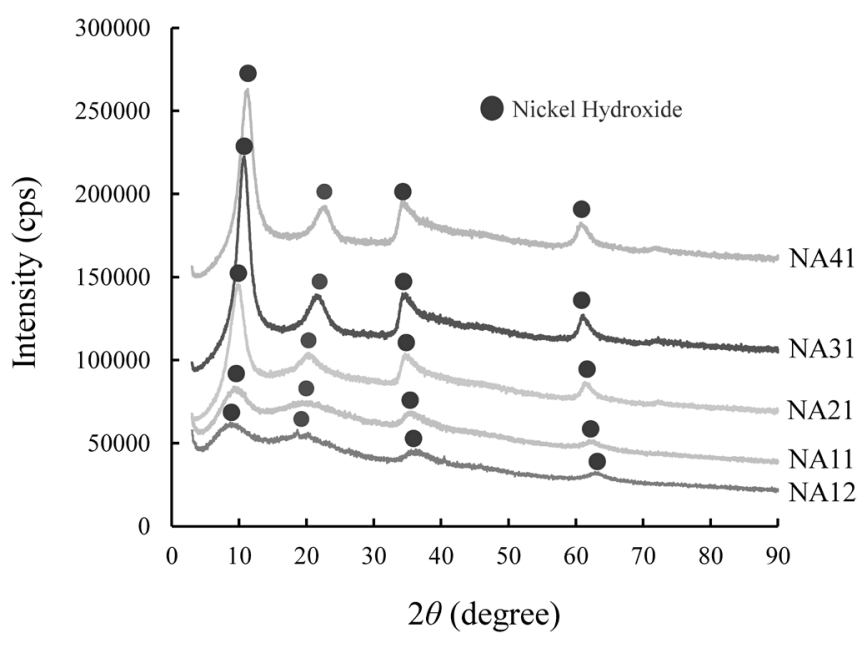

Fig. 2. XRD Patterns of the Adsorbents

Table 1. Properties of the Adsorbents

\begin{tabular}{cccc}
\hline \hline Samples & $\begin{array}{c}\text { Specific surface } \\
\text { area }\left(\mathrm{m}^{2} / \mathrm{g}\right)\end{array}$ & $\begin{array}{c}\text { Amount of hydroxyl } \\
\text { groups }(\mathrm{mmol} / \mathrm{g})\end{array}$ & Surface $\mathrm{pH}$ \\
\hline NA41 & 14.6 & 0.80 & 7.28 \\
NA31 & 11.7 & 0.82 & 6.50 \\
NA21 & 15.6 & 1.05 & 7.04 \\
NA11 & 22.8 & 1.92 & 7.98 \\
NA12 & 26.4 & 1.62 & 7.63 \\
\hline
\end{tabular}

(data not shown), which suggested that chromium(VI) ions combined with the NA11 surface and, at the same time, sulfate ions were released (the NA11 was prepared by sulfates). These results indicate that we could elucidate the adsorption mechanism of chromium(VI) ion from aqueous solution by NA11. Moreover, the number of base materials (nickel and aluminium) released from the NA11 adsorbent was lower than the amounts released by the single-component adsorbents (Table 2). Therefore, NA11 is most suitable for adsorption of chromium(VI) ion from aqueous solution. Finally, we selected 
NA11 as an adsorbent in the following experiments.

Effect of pH on the Adsorption of Chromium(VI) Ion The effect of the initial $\mathrm{pH}$ of the solution on the adsorption of chromium(VI) ion was investigated (Fig. 5(a)). In solution, chromium(VI) ion exists in the forms of $\mathrm{H}_{2} \mathrm{CrO}_{4}, \mathrm{HCrO}_{4}^{-}$, and $\mathrm{CrO}_{4}^{2-}$ at different ratios depending on $\mathrm{pH} . \mathrm{H}_{2} \mathrm{CrO}_{4}$ predominates at $\mathrm{pH}<1.0, \mathrm{HCrO}_{4}^{-}$predominates at $\mathrm{pH}$ 1.0-6.5, and

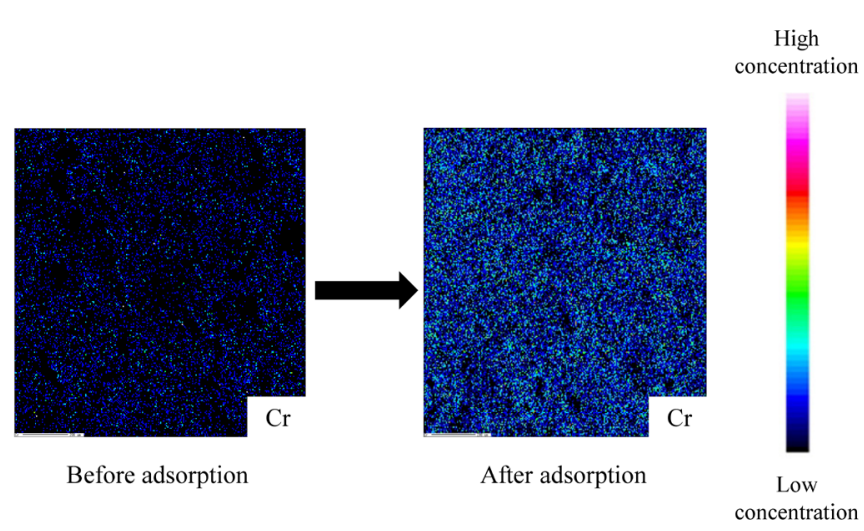

Fig. 3. Qualitative Analysis of NA11 Surface before and after Adsorption of Chromium(VI) Ion

(Color figure can be accessed in the online version.)

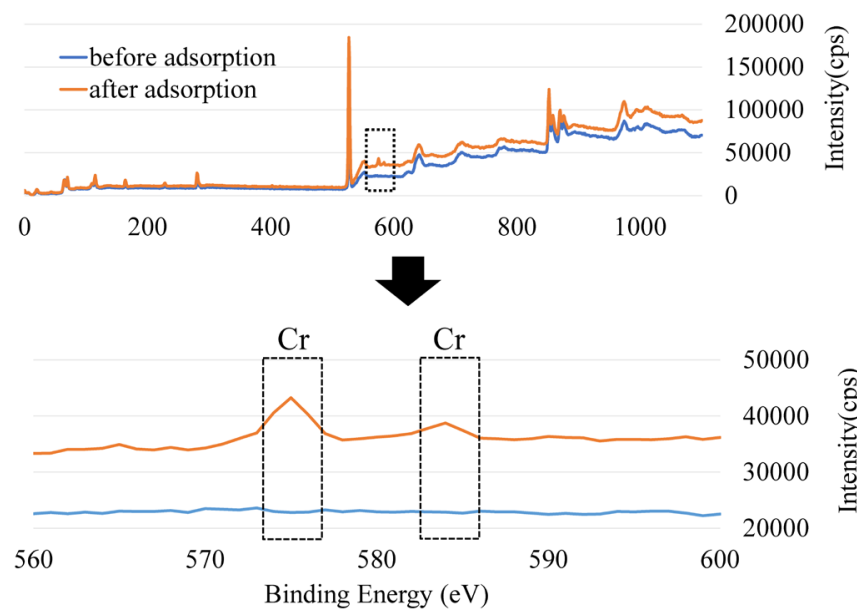

Fig. 4. Binding Energy of Chromium before and after Adsorption Using NA11

(Color figure can be accessed in the online version.) only $\mathrm{CrO}_{4}^{2-}$ is stable at $\mathrm{pH}>6.5 .^{24)}$ In addition, the isoelectric point $\left(\mathrm{pH}_{\mathrm{pzc}}\right)$ of NA11 was approximately 6.5 (Fig. 5(b)), indicating that the surface of NA11 was negatively charged at $\mathrm{pH}$ $>6.5$, and the amount of negatively charged chromium(VI) ion species increased, resulting in electromagnetic repulsion between $\mathrm{CrO}_{4}^{2-}$ and NA11 surface. ${ }^{25)}$ Moreover, the amount of hydroxyl ions increased in basic condition, which affects the ion exchange between chromium(VI) ions and sulfate ions. On the other hand, at the acidic condition ( $\mathrm{pH} 2.0)$, there are less suitable predominant species for adsorption of chromium(VI) ion $\left(\mathrm{H}_{2} \mathrm{CrO}_{4}\right.$ predominates at $\left.\mathrm{pH}<1.0\right)$. Therefore, the amount of chromium(VI) ion adsorbed decreased at $\mathrm{pH} 2.0$ in this study $(18.1 \mathrm{mg} / \mathrm{g})$.

Effect of Contact Time on the Adsorption of Chromium(VI) Ion To understand the adsorption process and transformation mechanism of chromium(VI) ion by NA11 better, the effect of contact time was investigated. Figure S3 shows the effect of contact time on the adsorption of chromium(VI) ion by NA11. The adsorption was an extremely fast process and reached equilibrium after $30 \mathrm{~min}$. Previous studies have reported that the time to adsorption equilibrium using $\mathrm{Ca}-\mathrm{Al}$ hydrotalcite, $\mathrm{Mg}-\mathrm{Al}$ hydrotalcite supported kaolin clay, CMC-LDH, Zr(IV) cross-linking chitosan magnetic microspheres, and attapulgite-supported nanoscale zero-valent iron was approximately $20 \mathrm{~min}, 30 \mathrm{~min}, 120 \mathrm{~min}, 300 \mathrm{~min}$, and $12 \mathrm{~h}$, respectively. Therefore, NA11 is useful for rapid removal of chromium(VI) ion from aqueous solution. , $^{1,3,5,10,25)}$

To investigate the reaction pathway and the rate-controlling mechanism of the adsorption process, adsorption kinetic data were further analyzed in terms of pseudo-first-order (Eq. (3)) and pseudo-second-order (Eq. (4)) kinetic models ${ }^{26,27)}$ :

$$
\begin{aligned}
& \ln \left(q_{e}-q_{t}\right) / q_{e}=-k_{1} t \\
& t / q_{t}=1 /\left(k_{2} q_{e}^{2}\right)+t / q_{e}
\end{aligned}
$$

where $q_{e}$ and $q_{t}$ are the amounts of chromium(VI) ion adsorbed at equilibrium and at time $t(\mathrm{mg} / \mathrm{g})$, respectively; $k_{1}$ is

Table 2. The Amount of Base Material Released from the Adsorbents

\begin{tabular}{lcc}
\hline \hline Samples & $\begin{array}{c}\text { Amount of aluminium released } \\
(\mu \mathrm{g} / \mathrm{g})\end{array}$ & $\begin{array}{c}\text { Amount of nickel } \\
\text { released }(\mu \mathrm{g} / \mathrm{g})\end{array}$ \\
\hline $\mathrm{Al}(\mathrm{OH})_{3}$ & $1.0 \times 10^{3}$ & - \\
$\mathrm{Ni}(\mathrm{OH})_{2}$ & - & $1.2 \times 10^{3}$ \\
$\mathrm{NA} 11$ & 0.6 & $1.1 \times 10^{3}$ \\
\hline
\end{tabular}

(b)

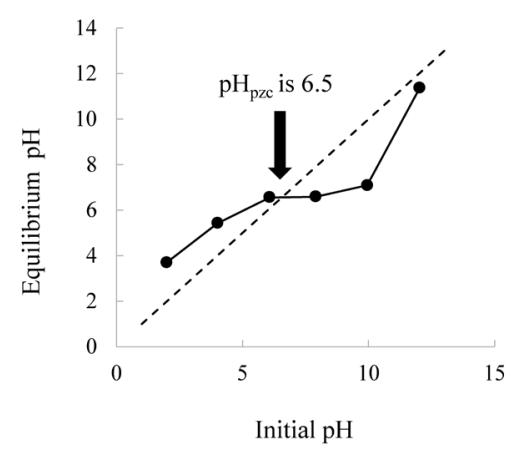

Fig. 5. Effect of $\mathrm{pH}$ on the Adsorption of Chromium(VI) Ion Using NA11 (a) and $\mathrm{pH}_{\mathrm{pzc}}$ of NA11 (b)

(a) Initial concentration: $100 \mathrm{mg} / \mathrm{L}$, adsorbent dosage: $0.1 \mathrm{~g}$, solvent volume: $50 \mathrm{~mL}$, temperature: $25^{\circ} \mathrm{C}$, contact time $24 \mathrm{~h}$. (b) Dotted line is $y=x$. 
the pseudo-first-order rate constant $(1 / \mathrm{h})$; and $k_{2}$ is the pseudosecond-order rate constant $(\mathrm{g} / \mathrm{mg} / \mathrm{h})$.

The kinetic parameters calculated from the models are summarized in Table 3. A comparison of the correlation coefficients of the two kinetic models suggests that the pseudosecond-order model $\left(R^{2}=0.998\right)$ is better at describing the behaviour of the adsorbent for chromium(VI) ion adsorption. The result indicated that the rate-limiting step should be chemical adsorption involving valence forces through an exchanging of electrons between adsorbent and adsorbate. ${ }^{1,28)}$

Effect of Temperature on the Adsorption of Chromium(VI) Ion The effect of different temperature on the adsorption capacity of chromium(VI) ion onto NA11 was investigated (Fig. 6). It was observed that the adsorption capacity increased with adsorption temperature (from 5 to $45^{\circ} \mathrm{C}$ ), indicating that higher temperature enhanced the diffusion rate and speed of adsorption.

The Langmuir (Eq. (5)) and Freundlich (Eq. (6)) adsorption isotherms are describing the interaction between the adsorbent and adsorbate:

$$
C_{e} / q_{e}=1 / W_{s} a+C_{e} / W_{s}
$$

where $C_{e}$ is the equilibrium concentration $(\mathrm{mg} / \mathrm{L}), q_{e}$ is the amount adsorbed at equilibrium $(\mathrm{mg} / \mathrm{g})$, and $W_{s}$ and $a$ are Langmuir constants related to the monolayer adsorption capacity and energy of sorption, and

$$
\log q_{e}=\log k+(1 / n) \log C_{e}
$$

where $k$ and $n$ are the Freundlich constants related to the adsorption of the adsorbent and the intensity of adsorption, respectively. ${ }^{29)}$

The Freundlich and Langmuir constants for the adsorption of chromium(VI) ion are shown in Table 4. According to the results obtained using the linear regression for the two models, the correlation coefficient of the Langmuir equation

Table 3. Fitting Results of Kinetic Data Using Pseudo-First-Order Model

\begin{tabular}{|c|c|c|c|}
\hline Fitting models & $\begin{array}{l}k_{1}\left(\mathrm{~h}^{-1}\right) \text { or } \\
k_{2}(\mathrm{~g} / \mathrm{mg} / \mathrm{h})\end{array}$ & $q_{e . c a l}(\mathrm{mg} / \mathrm{g})$ & $R^{2}$ \\
\hline Pseudo-first-order model & $7.4 \times 10^{-3}$ & 1.13 & 0.013 \\
\hline Pseudo-second-order model & $1.9 \times 10^{-5}$ & 17.99 & 0.998 \\
\hline
\end{tabular}
and Pseudo-Second-Order Model

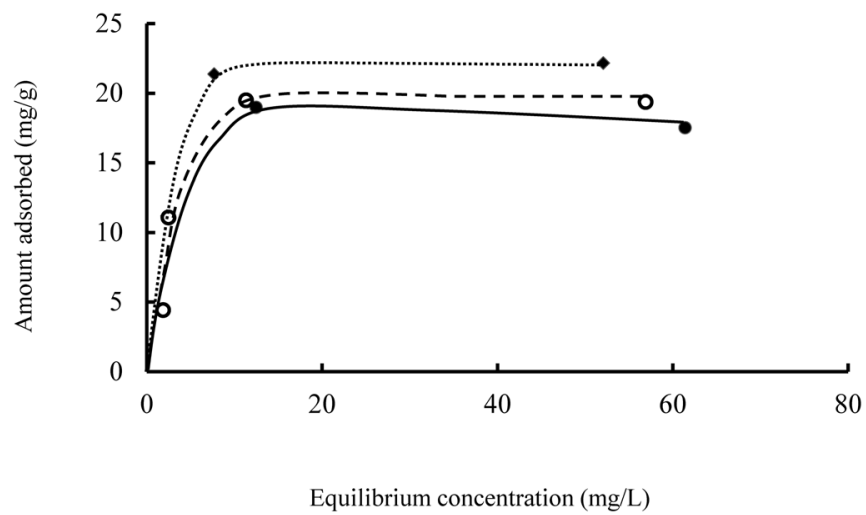

Fig. 6. Adsorption Isotherms of Chromium(VI) Ion onto NA11

Initial concentration: $10-100 \mathrm{mg} / \mathrm{L}$, adsorbent dosage: $0.1 \mathrm{~g}$, solvent volume: $50 \mathrm{~mL}$, contact time $24 \mathrm{~h}, 0: 5^{\circ} \mathrm{C}, \bigcirc: 25^{\circ} \mathrm{C}, \bullet: 45^{\circ} \mathrm{C}$.
$\left(R^{2}=0.984-0.992\right)$ fits well compared to that of the Freundlich equation $\left(R^{2}=0.605-0.642\right)$. The Langmuir isotherm model is based on the assumption that the adsorption sites are identical and energetically equivalent and that only monolayer adsorption occurs in the process. ${ }^{5,30)}$ Additionally, the value of $W_{s}(18.4-24.1 \mathrm{mg} / \mathrm{g})$ increased with increasing temperature, indicating that these behaviours are in agreement with the adsorption isotherms in Fig. 6. Finally, chromium(VI) ions were easily adsorbed onto NA11 surface when $1 / n$ was in the range $0.1-0.5$, but not when $1 / n>2$. The obtained results $(0.29-0.39)$ indicate that chromium(VI) ions were easily adsorbed in this experiment. ${ }^{31)}$

As mentioned above, the adsorption capacity of chromium(VI) ion using NA11 is related to the adsorbent surface and a chemical adsorption process involving valences through the exchange of electrons between adsorbent and adsorbate. Moreover, previous studies have reported that ion exchange is one of the adsorption mechanisms of the adsorbate. Therefore, we evaluated the relationship between the amount of chromium(VI) ion adsorbed and the amount of sulfate ion released from NA11 (Fig. 7). As shown in the figure, a positive linear relationship $(r=0.990)$ was observed in this study (the data used is the adsorption isotherm at $25^{\circ} \mathrm{C}$ ). These results suggest that sulfate ions interlayered in the NA11 are exchanged with chromium(VI) ions in the sample solution.

Adsorption Thermodynamics Thermodynamic analyses are appropriate for determining whether an adsorption is a physisorption or chemisorption process. The thermodynamic parameters, standard Gibbs free energy $(\Delta G)$, standard enthalpy change $(\Delta H)$, and standard entropy change $(\Delta S)$, were estimated by Eqs. (7) and (8):

$$
\begin{gathered}
\Delta G=-R T \ln K \\
\ln K=\Delta S / R-\Delta H / R T
\end{gathered}
$$

Table 4. Freundlich and Langmuir Constants on the Adsorption of Chromium(VI) Ion

\begin{tabular}{ccccccccc}
\hline \hline \multirow{2}{*}{$\begin{array}{c}\text { Temperature } \\
\left({ }^{\circ} \mathrm{C}\right)\end{array}$} & \multicolumn{3}{c}{ Freundlich constants } & & \multicolumn{3}{c}{ Langmuir constants } \\
\cline { 2 - 3 } \cline { 7 - 9 } & $1 / n$ & $\log k$ & $R^{2}$ & & $W_{s}(\mathrm{mg} / \mathrm{g})$ & $a(\mathrm{~L} / \mathrm{mg})$ & $R^{2}$ \\
\hline 5 & 0.39 & 0.85 & 0.608 & & 18.4 & 127.6 & 0.992 \\
25 & 0.29 & 0.76 & 0.642 & & 20.7 & 124.1 & 0.990 \\
45 & 0.39 & 0.78 & 0.605 & & 24.1 & 140.8 & 0.984 \\
\hline
\end{tabular}

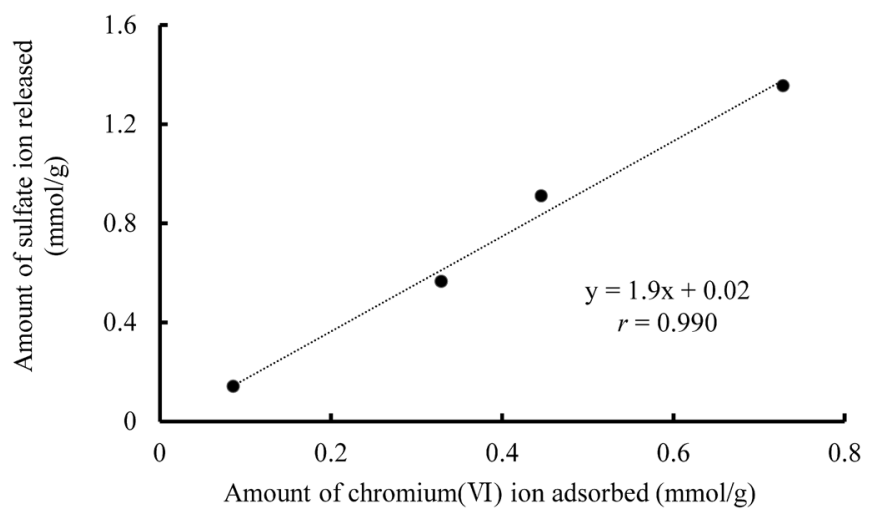

Fig. 7. Relationship between Amount of Chromium(VI) Adsorbed and Amount of Sulfate Ion Released Using NA11 
(a)

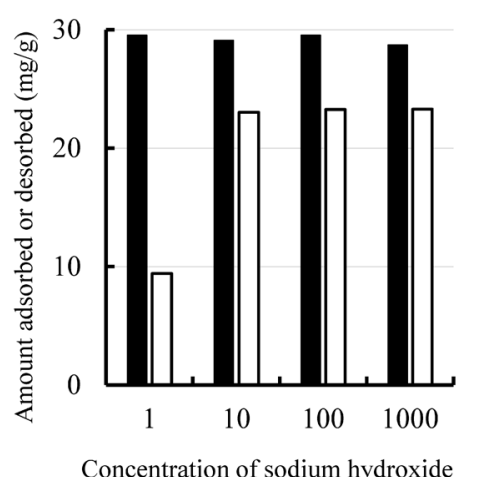

$(\mathrm{mmol} / \mathrm{L})$ (b)

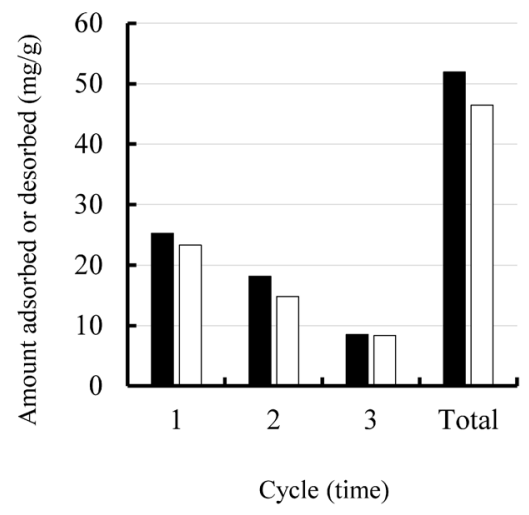

Fig. 8. Amount of Chromium(VI) Ion Adsorbed or Desorbed Using Sodium Hydroxide Solution

Adsorption condition, Initial concentration: $100 \mathrm{mg} / \mathrm{L}$, adsorbent dosage: $0.1 \mathrm{~g}$, solvent volume: $50 \mathrm{~mL}$, temperature: $25^{\circ} \mathrm{C}$, contact time $24 \mathrm{~h}$, desorption condition, solvent volume $100 \mathrm{~mL}$, temperature $25^{\circ} \mathrm{C}$, contact time $24 \mathrm{~h}$, $\mathbf{\square}$ : Amount adsorbed (mg/g), $\square$ : Amount desorbed (mg/g).

where $R$ is the universal gas constant $(8.314 \mathrm{~J} / \mathrm{mol} \mathrm{K}), T$ is the absolute temperature $(\mathrm{K})$, and $K$ is the adsorption equilibrium constant. Thus, $\Delta H$ and $\Delta S$ are determined from the slope and intercept. The thermodynamic parameters for chromium(VI) ion adsorption onto NA11 are shown in Table S1. All of the $\Delta G$ values were negative and the absolute value increased with temperature, indicating that the adsorption process was spontaneous and thermodynamically favourable. ${ }^{32)}$ The positive value of $\Delta S(9.16 \mathrm{~kJ} / \mathrm{mol})$ indicated an increase in randomness at the solid/solution interface during chromium(VI) ion adsorption. In addition, the value of $\Delta H(0.58 \mathrm{~J} / \mathrm{mol})$ suggested that the adsorption process in this study was endothermic. The magnitude of $\Delta H$ may provide some indication about the type of adsorption, where the two main types of adsorption are physical and chemical. Between physisorption and chemisorption, the former shows values less than $20.9 \mathrm{~kJ} / \mathrm{mol}$ and the latter shows values higher than $40 \mathrm{~kJ} / \mathrm{mol}^{32,33)}$ Therefore, the $\Delta H$ value implied that the adsorption of chromium(VI) ion onto NA11 was mainly by physisorption (specific surface area, etc.).

Desorption and Regeneration of NA11 The regeneration of the used NA11 using sodium hydroxide solution and subsequent re-adsorption were investigated to assess the reusability of NA11. Figure 8(a) shows the amount of chromium(VI) ion adsorbed/desorbed using sodium hydroxide solution at different concentrations. The amount of chromium(VI) ion adsorbed was approximately $29.2 \mathrm{mg} / \mathrm{g}$. It can be seen that the amount of chromium(VI) ion released from NA11 increased with increasing concentration of sodium hydroxide (desorption percentage was $32.0 \%$ for sodium hydroxide solution at $1 \mathrm{mmol} / \mathrm{L}$ and $79.0-81.0 \%$ for sodium hydroxide solution at $10-1000 \mathrm{mmol} / \mathrm{L})$. These results indicate that NA11 reuses after desorption using sodium hydroxide solution in this experimental condition. The re-adsorption of the used NA11 using sodium hydroxide solution was investigated. Cycles were performed up to three times, and the results are shown in Fig. 8(b). NA11 was recovered with a sodium hydroxide solution, and the recovered NA11 was recycled. The total amount adsorbed, the total amount desorbed, and recovery percentage were 51.9, 49.9, and $96.1 \%$, respectively. The amount of chromium(VI) ion adsorbed decreased with increasing number of cycles. However, in general, the adsorption/desorption

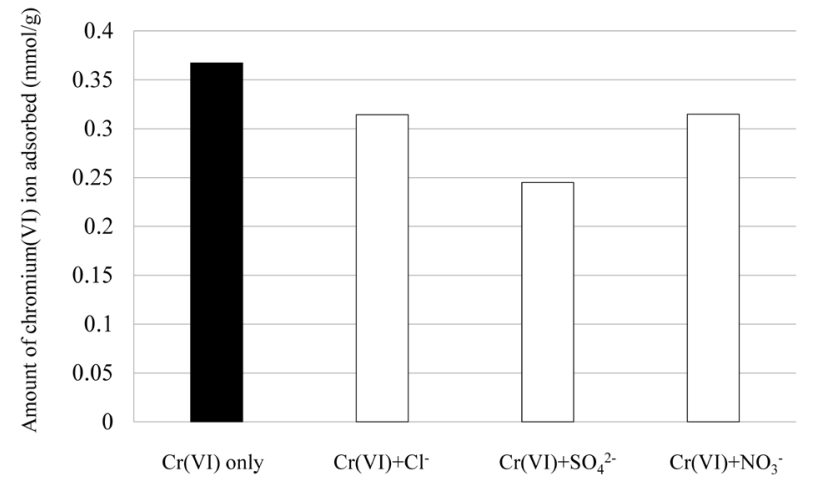

Fig. 9. Amount of Chromium(VI) Ion Adsorbed in Binary Solution System

Initial concentration: $1 \mathrm{mmol} / \mathrm{L}$, adsorbent dosage: $0.1 \mathrm{~g}$, solvent volume: $50 \mathrm{~mL}$, temperature: $25^{\circ} \mathrm{C}$, contact time $24 \mathrm{~h}$.

behaviours still prove that NA11 was recovered and reused for chromium(VI) ion adsorption using a sodium hydroxide solution as the eluent. In other words, NA11 has potential for practical application as a renewable adsorbent.

Effect of Coexistences on the Adsorption of Chromium(VI) Ion Using NA11 The amount of chromium(VI) ion adsorbed in binary solution systems is shown in Fig. 9. Three anions (chloride, sulfate, and nitrate) commonly found in environmental waters at varying strength were evaluated. The amount of chromium(VI) ion adsorbed in the binary solutions formed with chloride ion or nitrate ion decreased slightly compared to the value in a single solution. However, the high-valence sulfate anion could not be neglected. Sulfate ion had a more effect on the adsorption capacity of chromium(VI) ion. A similar trend was reported by a previous study. ${ }^{32)}$ Collectively, the adsorption capability results of chromium(VI) ion suggest that NA11 has a high affinity for chromium(VI) ion compared to other anions. This study of the physical and chemical characteristics of NA11 revealed that it is a potential adsorbent that may be improved further. ${ }^{10)}$

\section{Conclusion}

In this work, NA11 was used as an adsorbent for the adsorption of chromium(VI) ion from aqueous solution. The 
amount of chromium(VI) ion adsorbed onto NA11 was higher than the amounts adsorbed by other adsorbents. The adsorption capability of chromium(VI) ion onto NA11 was evaluated in terms of physicochemical characteristics. The optimal $\mathrm{pH}$ for chromium(VI) ion adsorption is an acidic condition $(\mathrm{pH}$ range from 4 to 6), and adsorption equilibrium was achieved within $30 \mathrm{~min}$. Moreover, the adsorption onto NA11 increased with increasing temperatures, indicating that the adsorption process is endothermic. The decrease in $\Delta G$ with increase in temperature (from -2.00 to $-2.20 \mathrm{~kJ} / \mathrm{mol}$ ) indicated an increase of feasibility of adsorption at higher temperature, which indicated that the nature of chromium(VI) ion adsorption onto NA11 is spontaneous. In addition, adsorbed chromium(VI) ion onto NA11 was easily desorbed by sodium hydroxide solution at different concentrations. NA11 was re-used for adsorption/ desorption of chromium(VI) ion at least three times.

Acknowledgment The Research Foundation for Pharmaceutical Sciences.

Conflict of Interest The authors declare no conflict of interest.

Supplementary Materials The online version of this article contains supplementary materials.

\section{References}

1) Chen X., Zhang W., Luo X., Zhao F., Li Y., Li R., Li Z., Chemosphere, 185, 991-1000 (2017).

2) Mohan D., Pittman C. U. Jr., J. Hazard. Mater., 137, $762-811$ (2006).

3) Deng L., Shi Z., Li B., Yang L., Luo L., Yang X., Ind. Eng. Chem. Res., 53, 7746-7757 (2014).

4) Selvi K., Pattabhi S., Kadirvelu K., Bioresour. Technol., 80, 87-89 (2001).

5) Tan L., Li H., Liu M., RSC Adv., 8, 12870-12878 (2018).

6) Cohen M. D., Kargacin B., Klein C. B., Costa M., Crit. Rev. Toxicol., 23, 255-281 (1993).

7) Mcean J. E., Mcneill L. S., Edwards M., Parks J., J. Am. Water Works Assoc., 104, 348-358 (2012).

8) Ogata F., Nakamura T., Ueta E., Nagahashi E., Kobayashi Y., Kawasaki N., J. Environ. Chem. Eng, 5, 3083-3090 (2017).

9) Ogata F., Iwata Y., Kawasaki N., Chem. Pharm. Bull., 62, 892-897 (2014).
10) Li Y., Wang J., Li Z., Liu Q., Liu J., Liu L., Zhang X., Yu J., Chem. Eng. J., 218, 295-302 (2013).

11) Pérez E., Ayele L., Getachew G., Fetter G., Bosch P., Mayoral A., Díaz I., J. Environ. Chem. Eng, 3, 1555-1561 (2015).

12) Ramos-Ramirez E., Gutierrez Ortega N. L., Contreras Soto C. A., Olguin Gutierrez M. T., J. Hazard. Mater., 172, 1527-1531 (2009).

13) Wang R. Z., Huang D. L., Liu Y. G., Zhang C., Lai C., Zeng G. M., Cheng M., Gong X. M., Wan J., Luo H., Bioresour. Technol., 261, 265-271 (2018).

14) Huang D., Liu C., Zhang C., Deng R., Wang R., Xue W., Luo H., Zeng G., Zhang Q., Guo X., Bioresour. Technol., 276, 127-132 (2019).

15) Ogata F., Kawasaki N., Chem. Pharm. Bull., 63, 1040-1046 (2015).

16) Ogata F., Imai D., Toda M., Otani M., Kawasaki N., J. Ind. Eng. Chem., 34, 172-179 (2016).

17) Ogata F., Ueta E., Toda M., Otani M., Kawasaki N., Water Sci. Technol., 75, 94-105 (2017).

18) Ogata F., Ueta E., Kawasaki N., J. Ind. Eng. Chem., 59, 56-63 (2018).

19) Ogata F., Nagai N., Kariya Y., Nagahashi E., Kobayashi Y., Nakamura T., Kawasaki N., Chem. Pharm. Bull., 66, 458-465 (2018).

20) Ogata F., Toda M., Otani M., Nakamura T., Kawasaki N., Water Sci. Technol., 3, 913-921 (2017).

21) Yamashita T., Ozawa Y., Nakajima N., Murata T., Nippon Kagaku Kaishi, 8, 1057-1061 (1978).

22) Japanese Industrial Standard Committee, JIS K 1474 (2007).

23) Yang K., Yan L. G., Yang Y. M., Yu S. J., Shan R. R., Yu H. Q., Zhu B. C., Du B., Sep. Purif. Tehcnol., 124, 36-42 (2014).

24) Butler J. N., "Ionic Equilibrium," Addison, Wesley, New York, 1967.

25) Zhang W., Qian L., Ouyang D., Chen Y., Han L., Chen M., Chemosphere, 221, 683-692 (2019).

26) Langergren S. Zur theorie der sogenannten adsorption geloster stoffe, K. Sven. Vetenskapsakad. Handl., 24, 1-39 (1898).

27) Ho Y. S., McKay G., Water Res., 34, 735-742 (2000).

28) Wang J., Zhang W., Yue X., Yang Q., Liu F., Wang Y., Zhang D., Li Z., Wang J., J. Mater. Chem. A, 4, 3893-3900 (2016).

29) Acelas N. Y., Martin B. D., López D., Jefferson B., Chemosphere, 119, 1353-1360 (2015).

30) Langmuir I., Trans. Faraday Soc., 28, 195-201 (1932).

31) Abe I., Hayashi M., Kitagawa M., J. Jap. Oil Chem. Soc., 25 145-150 (1976).

32) Chen C. R., Zeng H. Y., Xu S., Liu X. J., Duan H. Z., Han J., J. Taiwan Inst. Chem. Eng., 70, 302-310 (2017).

33) Zhang Z. Q., Liao M. C., Zeng H. Y., Xu S., Liu X. J., Du J. Z., Zhu P. H., Huang Q. J., Appl. Clay Sci., 102, 246-253 (2014). 